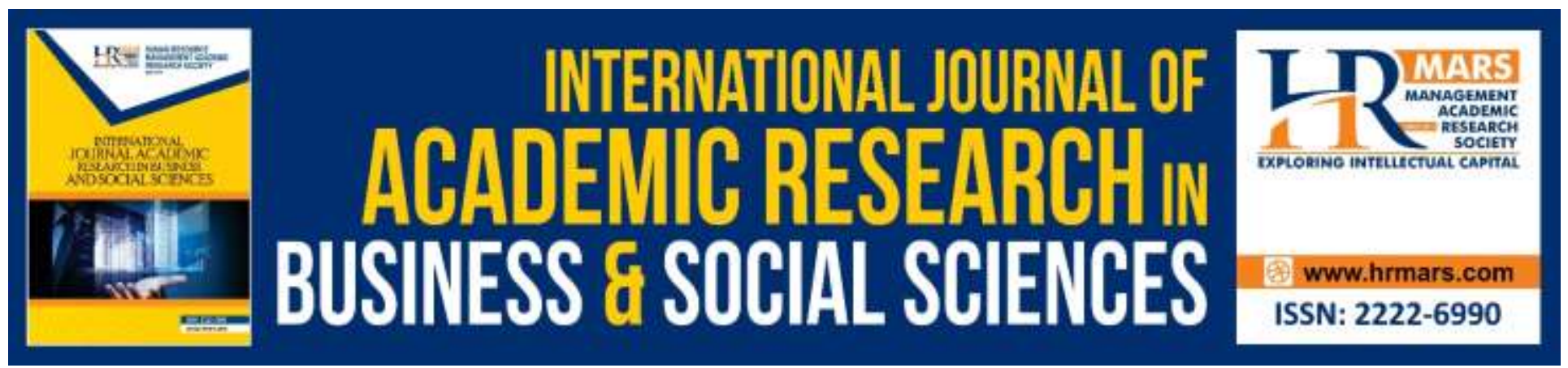

\title{
Strategy Implementation at Kakamega Teachers Savings and Credit Cooperative Society, Kenya
}

Simiyu Petronilla Avigoke, Odero Faith Auma, Aketch Ng'ong'a

To Link this Article: http://dx.doi.org/10.6007/IJARBSS/v9-i7/6100

DOI: $10.6007 /$ IJARBSS/v9-i7/6100

Received: 12 May 2019, Revised: 18 June 2019, Accepted: 01 July 2019

Published Online: 24 July 2019

In-Text Citation: (Avigoke, Auma, \& Ng'ong'a, 2019)

To Cite this Article: Avigoke, S. P., Auma, O. F., \& Ng'ong'a, A. (2019). Strategy Implementation at Kakamega Teachers Savings and Credit Cooperative Society, Kenya. International Journal of Academic Research in Business and Social Sciences, 9(7), 152-175.

Copyright: (C) 2019 The Author(s)

Published by Human Resource Management Academic Research Society (www.hrmars.com)

This article is published under the Creative Commons Attribution (CC BY 4.0) license. Anyone may reproduce, distribute, translate and create derivative works of this article (for both commercial and non-commercial purposes), subject to full attribution to the original publication and authors. The full terms of this license may be seen at: http://creativecommons.org/licences/by/4.0/legalcode

Vol. 9, No. 7, 2019, Pg. 152 - 175

http://hrmars.com/index.php/pages/detail/IJARBSS

JOURNAL HOMEPAGE

Full Terms \& Conditions of access and use can be found at http://hrmars.com/index.php/pages/detail/publication-ethics 


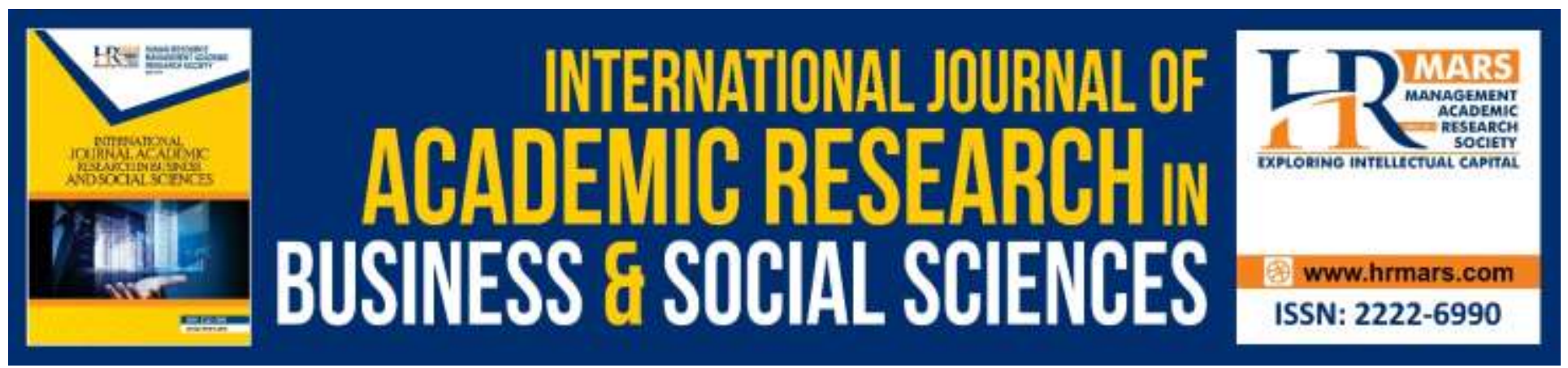

\title{
Strategy Implementation at Kakamega Teachers Savings and Credit Cooperative Society, Kenya
}

\author{
Simiyu Petronilla Avigoke, Odero Faith Auma, Aketch Ng'ong'a, PhD \\ Graduate, Master of Business Administration, School of Business, University of Nairobi, Kenya \\ PhD Student at School of Business, University of Nairobi, Kenya \\ Email: Pety2008@yahoo.com, faiodero07@gmail.com, aketchngonga@yahoo.com
}

Abstract: Strategy implementation is the most challenging stage of strategic management. Strategies that have been formulated have no value unless they are effectively translated into action. During the implementation process challenges may arise both from the internal and external environment. When these challenges occur, organizations should come up with ways that will help them combat, mitigate or sustain the challenges in the turbulent environment. This study intended to establish the challenges of strategy implementation at Kakamega Teachers Sacco and determine the measure taken by the Sacco to cope with the challenges of strategy implementation. To achieve this, an interview guide was administered to the senior management at Kakamega Teachers Sacco who are charged with the responsibility of implementing strategy. More data was also obtained from the relevant secondary documents that were availed by the Sacco. The data was collected basing on the selected departments as reflected in the interview guide. The raw data collected was checked and examined to ensure that it was complete and comprehensive. The findings of the study revealed that the Sacco had experienced several challenges when implementing their strategic plan. They include; inadequate resources, limited access to resources, lack of IT skills and IT equipments, outdated information technology, resistance to change, unsupportive culture, poor communication and lack of a reward policy. The study also established that the measures to strategy implication include; identifying new investments with high returns, adequate collateral and more guarantors should be a requirement for loan application, updating the information technology system, acquiring new members of the staff, training members of staff in relevant fields training them, developing an appropriate reward policy and establishment of a well stipulated protocol procedure. The study recommends that Kakamega teachers Sacco should come up with a team building programme and establish a marketing department. The study recommends that further studies be undertaken on; strategy formulation and evaluation, challenges of strategy implementation in other Sacco's and a longitudinal study on challenges of strategy implementation in the Sacco.

Keywords: Strategy Formulation, Strategy Implementation, Strategy Evaluation, IT, Kakamega Teachers Sacco, Challenges of Strategy 
INTERNATIONAL JOURNAL OF ACADEMIC RESEARCH IN BUSINESS AND SOCIAL SCIENCES

Vol. 9, No. 7, July, 2019, E-ISSN: 2222-6990 @ 2019 HRMARS

\section{Background of the Study}

Organizations exist in a turbulent environment and for that reason they are expected to survive and have a competitive advantage over their competitors. This has necessitated them to come up with strategies that will help them combat, mitigate or sustain the changes in the turbulent environment. Fedman and Kanter (1968) observed that organizational decisions are constrained by the actions of the organization itself; it's physical and mental characteristics, previous experiences of its members and by the social, political and economic environment of the organization. Organizations are therefore required to make sure that they formulate and implement their strategies in a way that will capitalize on their strength and maximize on the opportunities that are present in the external environment. For organizations to fit in the turbulent environment, they are required to re-align structures, systems leadership behavior, human resource, policies, cultures values and management processes (Michel and Russe, 2000).

According to the industrial economics theory before an organization enters the market it should first study the market structure, conduct and performance which are essential for an organization to position it in the market (Church and Ware, 2000). The systems theory holds that organizations are composed of several subsystems which are interconnected and they are in constant interactions with the environment. (Betchtold, 1997) Pears and Robinson (1988) Implementation processes involves significant changes in the organizations' structure, culture and systems. Organizations administration should bring change by working together through organizing; motivating, culture change building and finding a fit between strategy and the organization structure (Anyango, 2007). Failure to match these elements to strategies may lead to implementation challenges. Some of the challenges include; insufficient leadership, weak or inappropriate strategy, resistance to change, poor formulation and communication of the strategy, in adequate planning, inadequate resources, poor resource management and lack of fit between strategy and structure (Zook \& Allen, 2001; Hrebiniak, 2006; Noble, 1999; Alexander, 1985 Muthuiya, 2004; Kitutu, 2009). These hurdles pose serious challenges to strategy implementation and by developing an awareness of such barriers that lead to failure in implementation, firms can learn how to adapt their approach and develop tools to assist them in executing the strategy successfully.

The Sacco's are service cooperatives responsible for procurement, marketing and expansion services, loan disbursement, sale of consumer goods and member education. To achieve this, the SACCOs need to draw strategies plans and implement them to keep pace with the competitive business sector of the economy. Kakamega Teachers Cooperative is in particular one of the SACCOs that has developed a five year documented strategic plan, complete with implementation plan and indices of objective achievement for the period of 2007 - 2012.

\section{Concept of Strategy Implementation}

Lynch (2009) defines implementation as a process by which the organization's chosen strategies are put into operation. In order for organizations to implement policies and strategies more emphasis should be put on the design and management systems to enable them integrate people, structures, processes and resources of organizational objectives. He further notes that implementation processes involves planning new activities developing methods to control the implementation processes and considering what benchmarks will be needed to access the strategy .organizations 
should ensure that all this programs are adhered to Pears et el., (2010) observed that in order for the implementation processes to be successful short term objectives must be identified and functional tactics initiated. It is not enough just to formulate an appropriate strategy or to come up with an appropriate strategic plan. For effective strategy implementation, the strategy must be supported by decisions regarding appropriate organization structure, leadership, culture and the systems for rewarding performance as well as monitoring and controlling organizational action (Pearce \& Robinson, 1991).

According to Jones \& Hill (1997) implementation of strategy is a way in which a company creates organizational arrangement that allows it to pursue its strategy most effectively. Just as the strategy of the organization must be matched to the external environment, it must also fit the multiple factors responsible for its implementation (Bateman \& Zeithaml, 1993, David, 2000). Harrington (2006) defined strategy implementation as an interactive process of implementing strategies, policies, programs and action plans that allow a firm to utilize its resources and to take advantage of opportunities in the competitive environment. It is the process that turns plans into action assignments and ensures that such assignments are executed in a manner that accomplishes the plan's stated objectives. Noble (1999) looks at strategy implementation from a people perspective and argues that implementation is a multi-faceted, complex process of communication, interpretation, adoption and enactment of strategic plans.

According to Aosa (1992) once strategies have been developed, they need to be implemented; they are of no value unless they are effectively translated into action. Thus it is not enough just to develop strategies; efforts must be made to have clear and consistent guidelines for action. Strategy implementation includes the full range of managerial activities associated with putting the chosen strategy into place, supervising its pursuit and achieving the targeted results. Okumus (2001) pointed out that factors that can be identified as common for strategy implementation are strategy development, environmental uncertainty, organizational structure, culture, leadership, operational planning, resource allocation, people, communication and control. These are the factors that influence strategy implementation. Although formulating a consistent strategy is a difficult task for any management team, making that strategy work that is implementing it- is even more difficult (Hrebiniak, 2006). As pointed out by Yabs (2007) implementation challenges arise both from internal and external environments. Customer needs, technology and business environment are frequently changing and organizations have continued to plan and develop new strategies and flexibly adapt to the new environments. Even with rigorous planning, a new strategy often encounters various problems and challenges in its implementation (Mintzberg, 1994). To avoid unnecessary failures, Obara (2006) suggested that the strategy developed should be matched with implementation plans.

\section{Saving and Credit Movement in Kenya}

A Sacco is an association of persons united voluntarily to meet their common economic, social and their aspiration through a jointly and democratically owned enterprise (Nduti, 2012). The main aim of Saccos is to pool members scarce resources eliminate middle men and achieve common goals. Saccos are user owned, user controlled, and user benefited organizations. The movement is supposed to play an important role in wealth creation, food security and employment generation and hence participate in poverty alleviation. According to Ogunda (2009) there are over 11,200 registered 
cooperative societies country-wide. The membership is over 6.1 million and has mobilized domestic savings estimated at over Kshs.125 billion. The cooperatives have employed over 300,000 people besides providing opportunities for self-employment. Indeed, a significant number of Kenyans, approximately 63\% draw their livelihood either directly or indirectly from cooperative-based enterprises (Republic of Kenya 2007; International Monetary Fund 2007; The Kenya High Commission in the United Kingdom 2007).

The ministry of cooperatives, Development and Marketing made a major breakthrough by gazettement of Sacco Societies Bill in the year 2000. The bill was later introduced to the National Assembly. The bills proposal was to establish a new regulatory authority and provide a legal framework for licensing, regulatory and supervision of Sacco's. The society Regulatory Authority (SASRA) was inaugurated in 2009. Its mandate was to license Sacco's to regulate and supervise them to make sure that they abide with government financial instruments. (Cooperative Societies by Laws, Cooperative Act Chapter 490 of Kenyan Laws)

Sacco's are classified under the finance industry; players in the industry have experienced increased competition due to increased innovations and new entrants in the market. This has increased the complexity of managing Sacco's and it's a challenge for mangers in Sacco's. Magambo (2004) suggest that the ability to align with organizational objectives, insuring continues feedback on the strategic plan through measurement, monitoring and evaluation are key to successful strategic management process.

\section{Kakamega Teachers SACCO}

Kakamega Teachers SACCO was registered in 1977 by employees of the Teachers Service Commission in Kakamega District. The Society is based in Kakamega town and has 14,413 active members. The membership is set to rise because of teachers' recruitment by TSC and recruitment effort by the management. Although most of the members come from teachers under Teachers Service Commission (TSC), other members are drawn from employees of TSC secretariat, Office of the President, Kenya National Union of Teachers (KNUT) and Ministry of Education. The society has had a stable management and has remained very successful in its operations.

The core business of the society is to provide a savings avenue to members and advancing loans to them. This is still the focus of the society. Diversification opportunities will be looked into within the context of the core business. The feeling of the society is that success will come from concentrating on this initial core business. To provide efficient services the SACCO has set various strategies which are collated in the strategic plan document. The society operates a BOSA and FOSA. In order to continue offering more quality member-oriented services the Board has developed a five year Strategic Plan for the period 2007-2012. The SACCO committees of the Board of Directors include Finance and Administration Committee, Business Development and Education committee, Credit committee, Audit and Risk Management Committee. The Supervisory committee is also elected at the Annual Delegates Meeting. Every Board Committee meets regularly to discharge its mandate. The Society has also held its Annual Delegates Meeting every year and given dividends to its members. The Society is governed by 9 elected officials and a supervisory committee that consists of 3 
members. The operations of the Society are conducted by 45 staff members who are headed by a Chief Executive Officer. The Board is responsible for hiring, appraisal and dismissal of staff. However, the board is not involved in the day to day loan appraisal process which is currently being done by staff. Board members approve and also ratify loans after they have been disbursed (Kakamega Teacher's Sacco Strategic Plan for the period 2007-2012)

Since inception, the Society has undergone a series of transformation which include introduction of FOSA services. The Society's main aim is to promote the economic interests of members by encouraging thrift through the mobilization of deposits, savings and investments. Kakamega Teachers SACCO is one of the well-recognized SACCOs in Western Province and Kenya at large. This exemplified through the several awards won during the International Co-operative Day Celebrations. The Society collaborates with such organizations as the Co-operative Bank of Kenya, KUSCCO, CODIC, Cooperative Insurance Company and the Co-operative Alliance of Kenya (CAK). To achieve this, the SACCO has adopted various strategies including out sourcing of services of non-core business including development of strategic operational plan, sundry activities for instance cleaning and sanitation of business premises, security, automatic teller machine service provision, defaulted debt collection. The SACCO however directly deals with services to the members including member recruitment, member education, collection of member contributions, approval and advancing of loans to members, providing front office services, investing members contributions to earn profits.

\section{Research Problem}

The implementation process is the most challenging of all other stages of strategic management. 90 percent of well formulated strategies fail at the implementation stage. The remaining 10 percent are implemented but only 14 percent of the implemented strategies achieve their targets (Mintzberg \& Quin 1991). Eppler, Yang and Guohui (2008) note that after formulating a comprehensive strategy difficulties start to arise during the implementation processes. Key challenges may arise from organizations' failure to fully institutionalize and operationalize the strategies. In addition new developments from within the internal or the external environment may make previously developed strategies irrelevant hence posing a greater challenge. Organizations should therefore be informed that strategy formulation is entrepreneur and less challenging compared to implementation which is purely administrative and challenging (Asoa; 1992, Machuki 2005; Thompson Strickland and Gamble, 2007).

The Sacco movement in Kenya is growing tremendously and this makes the Sacco movement have several challenges especially in terms of strategy implementation. The challenges are due to the complex and divers demands placed on Kakamega Teachers Sacco by its members. The Sacco's leadership structure and operations must be re-aligned and enhanced in order to curb these challenges of strategy implementation. Kakamega teachers Sacco has not given strategy implementation and its challenges the seriousness it deserves compared to others components of strategic management and therefore the challenges are unique and contextual to Kakamega teachers Sacco.

A number of Research studies have been undertaken in the area of strategy implementation. Aosa (1992) studied an empirical investigation of aspects of strategy formulation and implementation in 
large private manufacturing companies. Musyoka (2001) carried out a study on the challenges faced in strategy implementation at Jomo Kenyatta Foundation. Machuki (2005) Studied challenges of strategy implementation at CMC Motors. Obara (2006) Studied challenges and strategy implementation at the electoral commission of Kenya (ECK). Gichohi (2007) studied the challenges of management at Unga Group Limited. Another study was carried out by Kimeli (2008) on the challenges of strategy implementation at the Kenya Revenue Authority (KRA).Owelle (2011) studied challenges of strategy implementation at Chemelil Sugar Company Limited. Kering' 2009 focused on implementation challenges of resource based strategy by Barclay Card Kenya. Kitutu (2009) studied challenges of strategy implementation at the ministry of public works. Kibathi 2009 Studied challenges of strategy implementation at Oxfarm Great Britain Kenya, and lastly Githaigai (2011) studied challenges facing the implementation of strategies within the Kenya Armed Forces Medical Insurance Scheme.

These case studies have highlighted that challenges are contextual and they cannot be generalized across the board. It's therefore important for the researcher to undertake a explicative study since there is no documented research on the challenges of strategy implementation at Kakamega teacher's SACCO nad this provides a gap. What are the challenges faced by Kakamega teaches Sacco in strategy implementation?

\section{Purpose of the Study}

The objectives of this study were:

i. To establish the challenges faced by Kakamega Teachers SACCO in implementing strategies

ii. To determine the measures taken by the management of Kakamega Teacher's Sacco in response to the challenges of strategy implementation.

\section{Theoretical Underpinnings}

Implementation of strategy has its theoretical underpinning drawn from two major theories namely the industrial organization economics theory and the open system theory. Theories provide a foundation of how an organization interacts with environment. The theories also provide valuable information to parties interested in strategy formulation, implementation and evaluation.

\section{Industrial Organization Economics Theory}

The Industrial organization economics theory suggests that before an organization enters the market it should first study the market structure conduct and performance of the market (Jacquemin, 2000). He further suggests that under the market structure organization should study the number of competitors who operate in the relevant market and their market shares, conditions of entry and exits, product standardization and proximity to suitable goods, interdependent between upstream and down quality of information controlled by partners and the degree of risk involved. Under Conduct, the organization should study the role of price and non price strategies and level of corporation established over times. Lastly it should look at the performance this is how the organizations are evaluated. This is because when the organization enters the market it will be in constant interaction with the environment and all this factors will affect its performance. 


\section{Open Systems Theory}

The interaction with others factors is illustrated in the open systems theory. Betchhold (1997) open system theory refers to the concept of organizations being strongly influenced by the environment. He further defines systems as a set of parts that interact with each other and function as a unified whole in an organization. An organization is seen as a sub-system of a large macro- system which may be identified as a sector industry or an economic zone. Jacquemin (2000) notes that an organization is therefore believed to be in constant interactions with the micro - system for it to survive it should formulate and implement strategies that will render it relevant in the market. Jacquemis notes further that open systems are a subject of differentiation and integration. Under differentiation the organizations subsystems are required to remain connected in order to sustain cooperate identity whereas under integration, the action parts are supposed to work together in order to achieve synergies. There are new developments in the open systems theory that show that organizational survival is dependent on the environment. This is evident in the chaos and complexity theories.

\section{Chaos Theory}

Levy (1994) defines chaos theory as the study of complex, nonlinear or dynamic systems. The reasons that lead to complexity in the environment includes probabilistic relationships among variables and the influence of the external systems, difference in unpredictability of social and physical systems which arise due to many interactions, non-linearity and inability to define starting conditions. This theory helps management to understand the impact of disruptions and assists them to know how to reduce volatility and the extent of disruptions in the environment (Levy, 1994). Betchhold (1997) suggest that in order to amplify deviations and anomalies in the environment management should introduce new patterns in the system, allow for open flow of information and work towards compatibility with the changing environment. According to Murray (1996) complexity arises from inter-relationship, interaction and inters connectivity of elements within a system and between a system and its environment. Connectivity, interdependence and co-existence are important for systems to function effectively. Mitleton \& Speh (2002) notes that Manager are therefore encouraged to create enabling environment and conditions favorable for the connectivity interdependence and co- existence of the subsystems.

\section{Strategy Implementation}

There is no universally accepted definition of strategy implementation. However, a number of definitions have been put forward. According to Kotler (1984) implementation is the process that turns plans into action assignments and ensures that such assignments are executed in a manner that accomplishes the plan's stated objectives. Harrington (2006) argues that strategy implementation is an iterative process of implementing strategies, policies, programs and action plans that allows a firm to utilize its resources to take advantage of opportunities in the competitive environment

According to Aosa (1992) once strategies have been developed, they need to be implemented; they are of no value unless they are effectively translated into action. Thus it is not enough just to develop strategies; efforts must be made to have clear and consistent guidelines for action. Strategy implementation includes the full range of managerial activities associated with putting the chosen 
strategy into place, supervising its pursuit and achieving the targeted results. To ensure success, the strategic plan must be translated into carefully implemented actions. Okumus (2001) analyzed the work of other authors and found that factors that can be identified as common for strategy implementation are strategy development, environmental uncertainty, organizational structure, culture, leadership, operational planning, resource allocation, people, communication and control.

Noble (1999) looks at strategy implementation from a people perspective and argues that implementation is a multi-faceted, complex process defined as the communication, interpretation, adoption and enactment of strategic plans. In this case it can be noted that the best-formulated strategies may fail to produce superior performance for the firm if they are not successfully implemented. All the specific techniques, actions and behaviors that are needed to make strategy implementation a success must be put in place and be customized to fit the particular organization's situation. Successful strategy implementation requires that the strategy is reflected in the way the firm organizes its activities, the key organizational leaders and the culture of the organization so that the strategy and the organization become one. Systems that provide strategic control and the ability to adjust strategies, commitments, and objectives in response to the ever changing future conditions must also be put in place by the implementers. Due to globalization and the rapidly changing business arena, organizations must make a serious commitment to be innovative in order to survive, grow and remain competitive (Pearce $\&$ Robinson, 2007).Strategy implementation is extremely important. If the organization manages a smooth transition from the strategy formulation stage and any change decided in strategic planning is successfully implemented, then all organizational members work as a team and align towards organizational goals. Therefore, effective strategy implementation primarily necessitates strategic consensus that can be achieved through clear and consistent guidelines and enhanced quality of strategic conversations, driven by reliable, trustworthy, responsible and confident managers.

\section{Challenges of Strategy Implementation}

According to Hrebiniak (2006) the real challenge of strategy implementation lies in the formulation and effective communication of vision, mission and values; commitment to projects and business results that will fulfill on the mission and the design of organizational architecture that allows for empowerment and communication. The strategy literature identifies formulation as the ends (objectives and goals) and implementation as the means (action plans and allocation of resources) of the strategy (Snow and Hambrick, 1980). Managers formulate specific strategies with expectations about how the strategy will transform into organizational objectives. They translate these strategies or action plans into internal processes that will implement the formulated strategy (Campbell et al, 2006). The quality of strategy formulation therefore has an effect on the quality of strategy implementation and poor strategy formulation may pose a challenge to strategy implementation.

A poor strategy-structure alignment is a necessary precursor to unsuccessful implementation of new business strategies (Noble, 1999). The alignment of organizational structure to strategy affects the shape, division of labor, job duties and responsibilities, the distribution of power and decision-making procedures within the company (Okumus, 2003). Organization structure groups similar tasks and 
activities and delineates roles and responsibilities. A good structure improves the efficiency of operations and balances the need for specialization with the need for integration. Poor organization structure poses a serious challenge in separation of duties and may result in overlapping roles and conflict of interest (Obara, 2006). A successful organization structure must not only take into account the vertical hierarchy but also the horizontal networks since without horizontal integration, knowledge sharing will be difficult.

Dobni (2003) describes culture as one of six C's (culture, co-alignment, core competencies, connection, customer value and communication) in creating a strategy implementation environment. She views culture as a major driver of strategy implementation. Implementation of a new strategy starts with an understanding of organizational culture and ends with a change in this culture to facilitate and embrace the strategy. Culture can be a real challenge to strategy implementation because it is close to change and often works as a major inhibitor of change. Thus a strategy cannot be successfully implemented without understanding the culture of the organization. Culture allows the adaptive behavior by the organization necessary for strategy implementation and as Obara (2006) pointed out, resistance to change; civil servant mentality and lack of skills to handle modern work challenges are major cultural challenges in strategy implementation. Culture must therefore be aligned with the new perceived realities and it begins with an understanding of the dynamics of the present culture and the assumptions that are held by the members of the organization.

Research has shown that people or the human resource can both intentionally and unintentionally influence strategy implementation success (Hamann, 2006). Since strategy implementation takes place over time and involves large parts of the organization, people stand at the centre of this process. Challenges in Human Resource may arise where management puts emphasis on controlling employees other that empowering them for the mission of the organization. The findings of Chimhanzi \& Morgan (2005) indicate that firms devoting attention to the alignment of marketing and human resources are able to realize significantly greater success in their strategy implementation. Strategy execution is the result of conscious attention, combining both leadership and management processes to describe and measure the strategy, to align it with internal and external organizational units and also align it with employees through motivation and targeted competency development programs. Human capital alignment is achieved when employees' goals, training and incentives become aligned with business strategy (Kaplan \& Norton, 2008).

Various studies in the recent past have proved that challenges of strategy implementation are contextual. Muthuiya (2004) carried out study that focuses on the NGO's. He undertook a study on challenges of strategy implication a case of African Medical Research foundation (AMREF) Kenya. The study revealed that inadequate resources and unsupportive culture were among the challenges faced by the organization in strategy implementation. Adongo (2008) looked at challenges to strategy implementation in health focused NGO's in Nairobi. The study revealed that structural aspect posed a challenge to strategy implementation. The studies focused on challenges of strategy implementation in NGO's but not in Sacco's hence providing a gap in knowledge that need to be filled. Koske (2003) focused his study on strategy implementation and its challenges in public corporation, 
INTERNATIONAL JOURNAL OF ACADEMIC RESEARCH IN BUSINESS AND SOCIAL SCIENCES Vol. 9, No. 7, July, 2019, E-ISSN: 2222-6990 @ 2019 HRMARS

the case of Telkom Kenya Ltd. The study revealed that poor resources, poor Management of resources, government regulations and limited information technology capacity were the Major challenges of strategy implementation. Olubonyi (2010) focused on challenges of strategy implementation at Kenya Ferry Services; the study revealed that financial limitation was the major challenge in strategy implementation.

Further studies such as that undertaken by Ochieng (2011) on challenges of product development strategy by Kenya Post Office savings revealed that inadequate financing, changing customers' needs, inadequate information and communication were key challenges in strategy implementation. Githaigai (2011) in his study about the challenges facing strategy implementation within the Kenya Armed forces Medical insurance Scheme revealed that lack of two-way communication and lack of effective management programmes were challenges faced by the organization in strategy implementation. Kering (2009) focused her study on implementation challenges of resource based strategy by Barclay-Card Kenya. Her study revealed that limited qualifications, lack of prior experiences, poor management and traditional performance reviews posed challenges to strategy implementation. These studies prove that the challenges are contextual and hence proving a gap in knowledge for more research to be carried out in different contexts.

Kitutu (2009) carried out a study that focused on the challenges of strategy at the Ministry of Public Works in Kenya. The findings of the study revealed that culture, poor compensation, lack of fit between strategy and structure, in sufficient communication, lack of coordination and support, outdated information technology, wrong strategic choices, government interference and regulations, poor management of resources, global trends in the industry and inadequate personnel skills posed challenges on strategy implementation in the organization. Kibathi (2009) undertook a study on challenges of strategy implementation at Oxfam Great Britain-Kenya. She categorized subsystems in the organization and referred to them as functional areas. These functional areas included: Human resource, finance, administration, logistics and communication. Under human resource she pointed out that budget constraints, employee turnover, inadequate technical skills and unwillingness of employees to work under harsh conditions were challenges faced to this functional area. Under finance inadequate resource and limited access to these resources posed a challenge. Administration faced the challenge of the tall structure. Inadequate human capital, unrealistic objectives and lack of sufficient preparation were challenges faced by the logistics area and lastly under communications conflicting proprieties and inadequate coordination were the major challenges. Mullei (2009) focused on challenges of liberalization by DT Dobie Limited. He found out that Employee incompetence, high customs duty, stringent import regulation and procedures and fluctuation in foreign currency were the major challenges of strategy implementation. All these studies are proof that strategy implementation are unique to the context.

\section{Measures to Mitigate Challenges of Strategy Implementation}

A properly instituted code of conduct that includes organizational policies and rules with specific guidelines on implementation is essential for strategy implementation. The context in which the policy operates is important. Formulating a policy requires a good understanding of local needs, 
opportunities and constraints, taking all stakeholders into account. There should be convincing attitude from the government with specific measures to empower the society and complementary measures from within the organization to foster quality and accountability (regulation, incentives and norms). Policies and rules are a challenge to strategy implementation. He argues that an organization without clear policies and rules governing management plans brings about conflict in roles and can hinder implementation of decisions resulting in non achievement of desired results (Obara, 2006).

According to Thompson et al., (2007), successful strategy implementers have a knack for diagnosing what their organizations need to do to execute the chosen strategy well and figuring out how to get things done. This means they must have the right skills, strong leadership traits and be confident of the specific actions to be undertaken to achieve desired objectives. The challenge to strategy implementation is to create a series of tight fits between strategy and budgetary allocation, strategy and the organizational competencies, capabilities and structure, strategy and policy, and between structure and the corporate culture. Inadequate planning and communication are two major obstacles to successful implementation of strategies (Alexander, 1985).

According to Obara (2006) strategy implementation starts with formulating the organization vision and mission that is, the purpose, philosophy, and goals. An analysis that reflects the firm's internal conditions and capabilities (Strengths and weaknesses) is then conducted. An assessment of the organization's external environment is carried out to identify the opportunities and threats. These are caused by competitors, political factors, legal and cultural factors, technology, economic conditions and environmental factors. Management evaluates each of the decision options in line with the organization's vision and mission and decides on the most optimal decisions. A selection of a set of long term objectives and grand strategies that will achieve the most desirable decision option is done followed by developing annual objectives and short term strategies. Implementation of strategic choices is done by matching people with task, structure, culture and traditions, policies and rules, technology, funds, reward and support systems (Michael \& Russel; 2000, David; 2000)

Nutt (1986) identified four types of implementation tactics used by managers in making planned changes: intervention, participation, persuasion, and edict. Nutt (1987) explains the four tactics as follows: Intervention refers to strategy adjustments during the implementation stage by introducing new norms and practices. Participation consists of articulating strategic goals and nominating a task force that develops and proposes corresponding implementation options. Persuasion consists of the tactic of using the involved parties to convince employees about the decided course of actions. The main mechanism for implementation in the edicts tactics (that relies on power and is characterized by absence of participation) is the issuing of directives (Nutt, 1997).

\section{Methodology of the Study}

The research was a case study. A case study method gave an in-depth and detailed understanding of a single entity being studied; it provides a fairly comprehensive and clear insight into an organization operation without comparing to another. Yin (1994) notes that a case study advances ones understanding of the phenomenon by exploring in- depth new territories and concepts in relation to 
a given context. Omolo (2009), Mulei (2009) and Ochieng' (2011) used a case study as their design and they were successful. The case study assisted them to provide detailed and intensive knowledge about their contexts. A case study enabled the researcher conduct an in-depth investigation of contextual issues in strategy implementation. It was the most appropriate since it is powerful for intensive investigation of a particular unit or situation (Kothari, 2008). The case study provided the researcher with descriptive information which assisted in meeting the objectives of the study.

The data was collected from both primary and secondary sources. Primary data was obtained using an interview guide. The interview was guided by the objectives of the study. It contained open ended questions which assist the researcher obtain information about the views, opinions, perceptions, feelings and attitude of the respondent. The interview targeted the top managers at Kakamega teachers Sacco; they included; the chief executive officer, Finance manager, credit controller manager, information manager, and Human resource manager. Secondary data was used to supplement the primary data collected. The data was obtained from relevant documents documented at Kakamega teachers Sacco. The data was from Communication such as notes, emails, memos, letters, reports minutes, the strategic plan 2008-2012 and company magazine information on the challenges and solutions to strategy implementation in the Sacco.

The data collected was edited to ensure that it is accurate and consistent with other facts gathered. Content analysis was used to analyze the data. It involved doing a word frequency count to identify words of potential interest with an assumption that the words that are mentioned most often are the ones that reflect the greatest concern. The data processed was descriptive. The analysis involved thematic comparison of words was which was collected from different heads of departments in the Sacco.

This was the preferable method to be used since the subject matter is difficult to analyze numerically. It assisted the researcher to describe and interpret the differences and similarities in the data gathered. The content analysis showed the challenges of strategy implementation at Kakamega Teachers Sacco and the suggested measures to these challenges.

\section{Study Findings}

\section{Strategy Implementation at Kakamega Teachers Sacco}

Strategy implementation is the act of putting the formulated strategies into action. The interviewees were asked whether the Sacco had a strategic plan, they pointed out the Sacco had a five year strategic plan in place with well formulated strategies and action plans. The interviewees also pointed out that despite the fact that the Sacco had overall strategies in place; every department had also its strategies and action plans well formulated. The researcher collected information based on departments the departments include; finance, credit control, information technology and human resource.

The study established that there were well documented strategies in the financial department at Kakamega teachers Sacco. The respondents noted that the strategies in the department were formulated in line with the general requirements of the overall strategies of the organization. It was noted that when recruiting staff to the department the recruits are expected to have relevant and 
sufficient skills in accounting and finance. In addition to the already acquired skills and knowledge in the relevant area, upon recruitment the recruited staff is equipped with knowledge and awareness of the financial management system at Kakamega teachers Sacco. Adequate trainings and seminars are often conducted whenever there are new developments in the financial area.

It was established that Kakamega teachers Sacco maintains a financial management system. This system ensures that the funds are well utilized; there is accountability, financial monitoring and effective reporting. The following measures were put in place to make sure that the financial management system was successful. An accurate reconciliation is done on the books of account on a monthly basis, the analysis of budgets and expenditures are also carried out often. The financial manager ensures that exposure is done in line with the agreed parameters and brief the C.E.O on a weekly basis. The respondent also said that a report on the financial management system is presented to the supervisory committee whenever there is a meeting. There is limited access to systems containing financial reports, this has been controlled by ensuring each staff member has a password and lastly there is an audit trail to ensure that each member of the staff has performed their duties in accordance with the laid down rules and regulations. Systems are renewed regularly to ensure efficiency and effectiveness in the financial department. They also noted that there is an internal auditing system put in place to analyze what is done by the financial department on regular basis.

The study established that in order to translate the strategies into action plans, the department has organized for in house training and attendance of seminars for its staff members especially on prudential monitoring standards. It was also observed that measures had been put in place to ensure that members of the staff receive regular training by ICPAK to keep them up to date with the improvement in the profession.

The study observed that there were documented strategies in the credit control department. To translate strategies into action plans the department had put the following measures in place; plans were put in place to sensitize customers about the products of the department through seminars, notices and brochures, the loan application forms had been reviewed in order to reflect the current requirement. Guarantors were to be increased and an assurance of adequate collateral for loan application, a follow up procedure of monthly remittances from TSC and other employers was put in place to ensure effective recovery and remittance of fund.

The study sought to establish comments on the availability, access and utilization of resources. The respondent noted hat the availability and access to resources had improved gradually over the years, they also noted that the resources were scarce because they depended majorly on TSC and a few employees whose remittance was inadequate compared to the requirement of strategy implementation.

The study established that there were documented strategies in the information technology department. The study noted that there were action plans developed to ensure that appropriate 
procedures are put in place to match the Sacco's information technology requirements. They include; continuous review and upgrading the information system to march the market tends, linking the society with relevant service providers (e.g. co-operative bank in providing ATM machine), training the staff on current and required software, frequent update of set up websites and online back-ups. It was observed that this action plans not only do they affect the information technology department but rather the whole staff of the Sacco because the operations of the department is key in the operations of all the departments at the Sacco. When the action plans were being developed all other departments were involved to make sure that understand them clearly.

It was established that there exist strategies documented in the human resource department. In order to implement the documented strategic the Sacco has organized its structure in an integrated manner that makes the organization work as a team. The respondent pointed out that communication channels used by the Sacco included, memos, circulars which were sent to members of the staff through the various heads of departments. The interviews also noted that the senior management team which is composed of the C.E.O and the heads of departments' convened regular meetings to ensure that all the departments were updated about the progress of strategy implementation. In these meetings, challenges at departmental level were pointed self. Although most members of the staff had embraced the strategy implementation process as noted by the respondent, it was also evident that some members of the staff resisted it through failure to strictly adhere to the policies and procedures laid down for the success of strategy implementation and this posed a great challenge.

The study established that most of the managers had been trained in their respective areas of specialization. The respondent indicted that it was important for the staff to be trained in the skills required by a strategic plan for a given period before the commencement of the strategy. This will enable them to have a clear picture of what is required of them and equip them with knowledge about strategy. The study established that there is no documented reward policy to motivate the staff during the implementation process.

The respondents were asked to state whether the leadership was supporting the strategy implementation process. The respondents were quick to point out that the senior management team was providing an enabling leadership for the implementations process. This was evident in the regular meetings held where the progress and challenges were raised and discussed.

\section{Challenges of Strategy Implementation at Kakamega Teachers Sacco}

Under this section the researcher intends to answer the first objective which is to establish the challenges of strategy implementation at Kakamega teachers Sacco. The Sacco just like any other organization has experienced several challenges during the process of strategy implementation. The study was carried out on the selected departments in the organization which include; finance, credit control, information technology. The study also intended to establish whether their were any general challenges of strategy implementation that faced the organization 
When asked whether the resources allocated to the finance department were adequate enough to support successful implementation of strategy, the interviewees indicated that lack of adequate resources and limited access to resources wer4e the main challenges. The interviewees pointed out that there were limited resources and this was as a result of depending majorly on remittance from the teacher's service commission. The inadequate resources had posed a challenge in strategic implementation and this had dragged them in to heavy borrowing. The respondent also pointed out that the procedures put in place in relation to accessing resources were a challenge to the department making it difficult for them to access some resources. One of the interviewee said, "We have a problem when it comes to accessing resources because a requisition has to go through the head of department, senior management team, the CEO, the supervisory committee and lastly the board of governors. Most people who are involved tend to be over protective on resources and this makes it very difficult for both the management and the employees to access the resources." While the respondents indicated that their was a finance management system in place in the organization they were also quick to point out that poor maintenance of books of account which resulted from laxity and negative attitude towards work by some members of the staff.

In the credited control department it was established that the department faced a number of challenges. The main task of the department was to come up with several loan products and offer them to customers because lending is the core activity of the Sacco. When asked to state whether the department had enough resources, the interviewees were quick to point out that lack of adequate financial resources was the main problem faced by the department making it impossible for them to meet some loan demands especially those that required large amounts. The interviewees said that this problem was brought about as a result of high default rate from the customers and inadequate budgetary allocation. "We also do not have enough human resources to help as run this department; this is because the department is also mandated to market the products of the Sacco. Most members have not been trained in the field of marketing hence making it difficult for them to market the products as expected." said one of the respondent.

In the information technology department the respondents pointed out that outdated information technology was a major challenge. This was as a result of a leadership which didn't encourage development in information technology due to lack of knowledge and interest in the field of information technology. When asked whether there was adequate human capital, the respondents said that inadequate human capital in terms of capacity and skills was a greater challenge to the department. The respondent also pointed out that the ever changing global trends were a challenge since it was quite difficult for the members of the staff to cope with these changes at a short notice since those changes required some training before adoption. Lack of enough ICT equipment in the department made it difficult for the staff to execute their duties in the strategy development process.

The study established that there were a number of challenges in human resource department. When asked whether the communication process supported strategy implementation, the respondents said that undirected communication either from the top or from the bottom in the Sacco slowed down the flow of information causing confusion and on some occasions coursed inadequacy of information 
to those implementing the strategy. When asked to comment on resistance to change among the employees the respondents said that there was resistant to change from a number of employees which was brought about by about by lack of proper communication of the strategic plan and involvement of employees at the formulation stage. Concerning culture the informants indicated that unsupportive culture was also a challenge and it manifested itself through inadequate skills of the staff and their incompetence while performing their duties. When asked if there was a reward system in place for the employees the informants were quick to point out that there was no reward policy in the organization for the employees and had led to lack of motivation and initiative by the members of the staff. When asked to comment on the skills of the employees the interviewees noted that the staff had inadequate skills in some areas especially in the information technology area.

When asked whether the structure was well matched with and supportive of the implementation process, one of the respondent said that, "The structure that is in place had unnecessarily long procedure which led to time wastage and hence delaying the decision making process." The respondent also said that the existing structure had resulted into lack of authority in some heads of departments because the management at the top, that is the board of directors and the supervisory committee had more powers compared to the heads of department. Lack of authority among the heads of department left more matters unattended to.

The Sacco also faces challenges from the external environment. The respondents were asked to comment on how competition affected the implementation process, one of the respondent said, "Our products as a Sacco are facing stiff competition from other players in the financial sector. Most banks and microfinance institutions had reduced their interest rates on loans. For instance; Faulu Kenya has an interest of $12 \%$ on all loan products, Kenya Women Finance Trust have their rates at $11.5 \%$ and Women enterprise funds has it at $8 \%$ while our percentages range from $12 \%-18 \%$ depending on the type of loan. " the respondents said that their products were only limited to individuals where as other Sacco's such as Mwalimu Sacco had embraced group funding. The respondents also noted that they faced competition on loan requirements where loans to be given were pegged on the amount of shares where as in banks it was pegged on the ability to pay. The respondent also said that the Sacco had no marketing department and as a result most of their customers were not aware of the products offered whereas their customers such as Faulu Kenya have adverts on posters, in newspapers, on radio and even on television.

When asked whether the running of the Sacco was influenced by any political forces, the interviewees said that the Sacco was facing influence from the two teachers unions that is KNUT and KUPPET. The respondent pointed out that the two unions influenced the selection of members of the board of directors and those of the supervisory committee and also the recruitment of some employees to various posts. 
INTERNATIONAL JOURNAL OF ACADEMIC RESEARCH IN BUSINESS AND SOCIAL SCIENCES Vol. 9, No. 7, July, 2019, E-ISSN: 2222-6990 @ 2019 HRMARS

\section{Measures put in Place by Kakamega Teachers Sacco in Mitigating Challenges in Strategy Implementation}

The study also intended to find out if the Sacco had any measures put in place to cope with the challenges that were pointed out. It was established that although the challenges were pointed out from the departmental level they in one way or another affected the whole organizations during the strategy implementation process. The measures taken applied to the organization as a whole because the departments are viewed as subsystems which are in constant interaction.

The study established that the Sacco had conducted an assessment on the internal environment to enable them access their strength and weakness. This has assisted them source for enough funds to cater for its budgetary requirements to implement the strategic plan. The assessment has also assisted them realign their structure in a way that has created a fit between the strategy and structure. This was done through a review of the long structure.

The study also established that the Sacco had formulated appropriate policies that have spells out the procedures of communication, code of conduct and roles and duties to the members of the staff. These has assisted them do away with poor communication, and unsupportive culture. This has also helped to review the duties of the heads of department who have been given more powers in executing their duties.

Concerning the issue of stiff competition the Sacco has established marketing departments which has laid down marketing strategies that will see the Sacco indulge in massive advertising and formulation of new products with relatively low interest rates to attract and maintain their customers. The Sacco has plans to procure the recruitment process to make sure that the process is free and fare and only the qualified were employed

Concerning the out dated technology the organization has procured a new information system. Funds have been set aside to facilitate the IT staff to attend seminars and workshops organized by stakeholders in the field of IT to assist them acquire knowledge about the ever changing technology. The employees are trained regularly in order to acquire the required skills in IT.

Concerning organization had drawn well spelt procedures of the protocol for communication in the organization. The members of staff were being involved during the strategy formulation process to enable them own the strategic plan before they start implementing it. The organization is developing a good reward policy that will help motivate the employees during the implementation process. Concerning lack of adequate skills the organization was conducting training need assessment through resource persons and workshops, this has enable the organization develop appropriate training programmed such as sponsoring staff for residential courses, conducting in house trainings and organizing for exposure visits for members of the staff 


\section{Discussion of Findings}

The study established that the organization had evaluated its external environment as stated in their strategic plan and identified some of the competitors, conditions of entry and exit, product standardization, independence between and among players information controlled by partners' and the degree of competition (Jacquemin, 2000, Kakamega teachers Sacco strategic plan 20072012).The Sacco has subsystems which are referred to as departments (Betchtold, 1997). The subsystems can be compared to those of Oxfam Great Britain, Kenya as established by Kibathi (2009) in her study, she pointed out that the organization had sub- systems which she referred to as functional areas. The departments are also in constant interaction with the environment; this is evident through the external factors that have affected the environment. They include; competition from other financial institutions such as banks, microfinance institutions and other Sacco's, political influence from the teachers unions i.e. KNUT and KUPPET and rapid changes in technology have also affected the organization. From the theories it can be concluded that Kakamega Teachers Sacco exist in financial sector and has subsystems inform of departments

The Sacco also faces several challenges in strategy implementation which include: inadequate resources, limited access to resources, lack of IT skills and IT equipments, outdated information technology, resistance to change, unsupportive culture, poor communication and lack of reward policy, competition, politics, and unsupportive structure. These challenges are similar to those pointed out by other researchers in their studies such as those carried out by; Koske, 2003; Olubonyi, 2010, Muthuiya, 2004; Githaigai, 2011 and Kibathi (2009). Koske (2003) in his study he found out that limited technology was a challenge to strategy implementation, Olubony (2003) in his study revealed that financial resources were a major challenge. Muthuiya (2004) in his study he established that unsupportive culture was a challenge to strategy implementation. Contrary to other studies a study carried out by Kibathi (2009) revealed that Oxfam Great Britain Kenya organization had resources in abundance.

On measures taken by Kakamega Teacher's Sacco to cope with the challenges of strategy implementation. The study established that Assessment of the internal environment, Formulation of Appropriate policies, Procuring a new IT system, hiring and training more staff and developing an appropriate reward system. The study agrees with other studies carried out by Mulei (2009) who established that acquiring a new IT system is a measure to challenges of strategy implementation, contrary to that carried Kitutu (2009) who established that IT system should be outsourced . Mulei (2009) also established that massive advertising and product differentiation was key to mitigating the challenges of strategy implementation. The study also agrees with a study carried out by Mulei (2009) who established that developing training programs for employees was a measure to challenges of strategy implementation creating policies that will ensure effective communications during strategy implementation is advocated for by researchers such as Kering, 2009; Kitutu, (2009) and Mulei, (2009) just as it is in this study 
INTERNATIONAL JOURNAL OF ACADEMIC RESEARCH IN BUSINESS AND SOCIAL SCIENCES

Vol. 9, No. 7, July, 2019, E-ISSN: 2222-6990 @ 2019 HRMARS

\section{Conclusions and Recommendations \\ Conclusion}

The study concludes that Kakamega Teachers Sacco exists in the financial sector and it is in constant interaction with other players in the sector such as banks and Micro finance institutions. The organization has departments which are interconnected hence conforming to the organization and systems theories. The subsystems which the researcher in this study referred to departments were also discussed by Kibathi (2009) in her study and she referred to them as functional areas. This is in line with open systems theory propounded by Betchhold (1997) that an organization is a set of parts that interacts with each other and functions as a unified whole of an organization.

The study also concludes that the Sacco faced challenges during its strategy implementation process. The challenges include: inadequate resources, unsupportive structure, unsupportive culture; outdated information system, poor communication, resistance to change, lack of a reward system, stiff competition and politics from teachers unions. Other studies were carried out by other researchers such as Mulei (2009), Kering' (2009) Kitutu (2009) and Mbugua (2009). Their Studies revealed that one or more challenges that faced Kakamega teachers Sacco were also faced by the Organizations they researched on and this is because they operate in the same environment. Although most of the researchers pointed out lack of resources to be a major limitation other studies such as that done by Kibathi revealed that Oxfam Great Britain, Kenya had resources in abundance. This corroborates with chaos theory propounded by Levy (1994) which helps management to understand the impact of disruptions and assist them to know how to reduce volatility and extent of disruptions in the environment.

Lastly the study concludes that the measures taken by the Sacco to cope with challenges of strategy implementation include: assessment of the internal environment, formulation of appropriate policies. Procuring a new IT system, hiring and training more staff developing an appropriate reward system upon enactment of the measures the Sacco will be in a position to mitigate most of the challenges. These measures are consistent with those pointed out by Mulei regarding IT advertising and Human Resources contrary to Kitutu (2009) who suggests that IT be outsourced. This is in line with industrial organization economic theory by Jacquem (2000) that before an organization enters the market, it should first study the market structure conduct and performance of the market.

\section{Recommendations for Policy and Practice}

The findings of the study indicate that there exist challenges during strategy implementation process and therefore the management at Sacco should be aware of the challenges they may encounter during strategy implementation. The study has also enlightened the management on some of the responses suitable to solve the challenges encountered.

The study has also emphasized on teamwork amongst different departments, this will assist the department work together towards the success of strategy implementation. The study recommends that in order for the organization team work during strategy implementation, the Sacco should organize for team building programs in order to strengthen team work and a strong work force which will enable the departments work as a single unit during the implementation process. This will also enable the staff own the implementation process. 


\section{Limitation of the Study}

There is no study that can be complete without any limitations and this was no exception. Strategy management has three stages that are formulation, Implementation and evaluation. This study was only limited to the implementation stage. It would have been of more importance if the researcher would have researched on the three stages in order to get more information on strategic management from the Sacco.

Secondly this study was limited only to Kakamega Teacher's Sacco. This study only established the challenges of strategy implementation at Kakamega Teacher's Sacco and measures taken to cope with the challenges. These challenges can not be generalized because they are unique to the context. It would have been valuable if a similar study was curried out in other Sacco's and a comparison made.

Lastly, the study was limited to case study. It would be of more importance if the study had carried out a longitudinal study and the result compared over a period of time. This would have enabled the researcher to establish whether there are changes in the challenges and ways of dealing with them.

\section{Suggestions for Further Research}

The researcher suggests that more research be undertaken on strategy formulation and evaluation. This will enable the researcher to have a dear understanding of the whole research processes.

A study should also be carried out in other Sacco's to find out the challenges of strategy implementation and the measures taken to cope with these challenges of strategy implementation. This will assist the researcher to compare the challenges facing the Sacco's in strategy implementation and make a conclusion to whether they are unique to the context or they can be generalized.

A replica study should be done at the Sacco after sometime to find out if there are any changes that have taken place in strategy implementation. A comparison should be carried out with the current study to establish the similarities and differences. From this the researcher will be able to make more valid recommendations.

\section{References}

Alexander, L. (1991). Strategy Implementation: Nature of Problem in Hassey, D (Eds), International Review of Strategic Management 2 (1):73 - 96.

Anyango, A. (2007). Challenges of Strategy Implementation: A Survey of Multinational Manufacturing Companies in Kenya (Unpublished MBA Research Project), School of Business, University of Nairobi, Kenya.

Aosa, E. (1992). An Empire Investigation of Aspect of Strategy Formulation and Implementation within Large Private Manufacturing Companies in Kenya (Unpublished PHD Thesis). Starclyde University, Glasgow.

Bechtold, B. L. (1997). Chaos Theory 959 Model for Strategy Development in Organizations 4:219-224.

Chandler, A. D. (1962). Strategy and Structure. Chapters in History of the American Industrial Enterprises, Cambridge. MIT Press.

Church and Ware, R. (2000). Industrial organization a strategic Approach Adobe Reader version. Retrieved from htt://works.bepress.com/Jeffrey-church/23-Lynch 
INTERNATIONAL JOURNAL OF ACADEMIC RESEARCH IN BUSINESS AND SOCIAL SCIENCES

Vol. 9, No. 7, July, 2019, E-ISSN: 2222-6990 @ 2019 HRMARS

David, F. R. (2003). Strategic Management: Concepts and Cases (19 ${ }^{\text {th }}$ Ed.), Upper Saddle River, NJ: Prentice-Hall.

Dobni, B. (2003). Creating a Strategy Implementation. Business Horizons 46: 43-6.

Eppler M. J., Yang, L. and Guohui, S. (2008). Making Strategy Work: A Literature Review on the Factors Influencing Strategy Implementation. ICA working paper 2/2008.

Hambrick, D. and Cannela, A. (1989). Strategy Implementation as Substance and Selling. The Academy of Management Executive, 3 (4):278-285.

Hamman, P. (2006). Strategy Implementation Creates Business Results.

Hannan, M. and Freeman, J. (1984). Structural Inertia and Organizational Change.American Sociological Reviews 49:149-164.

Harrington, R. J. (2006). The Moderating Effects of Size, Management Tactics and Involvement in Strategy Implementation in Food Services. Hospitality Management, 25:373-397.

Hrebriniak. L. and Joyce, W. (1984). Implementation Strategy Macmillan, New York.

Kakamega Teachers Sacco Strategic Plan 2007-2012.

Kaplan, R. S. and Norton, D. P (2008). Leadership and Strategy for the Twenty First Century; Mastering the Management Systems. Harvard Business Review, $62-70$.

Kering, A. K. (2009). Implementation Strategy of Resource Based Strategy by Barclays Bank, Kenya (Unpublished MBA Project). School of Business, University of Nairobi, Kenya.

Kibathi, J. (2011), Challenges of Strategy Implementation in Oxfam, Great Britain, Kenya (Unpublished MBA Project). School of Business, University of Nairobi, Kenya.

Kitutu, M. M. (2009) Challenges of Strategy Implementation in the Ministry of Roads Kenya (Unpublished MBA Project). School of Business, University of Nairobi, Kenya.

Kimeli, D. K. (2008). Challenges of strategy implementation at Kenya Revenue Authority. (Unpublished MBA project). School of Business, University of Nairobi, Kenya.

Koske, F. K. (2003). Strategy Implementation and its Challenges in Public Corporations:The case of Telkom Kenya. (Unpublished MBA project). School of Business, University of Nairobi, Kenya.

Kothari, (2008). Research Methodology. Methods and Techniques. (2 ${ }^{\text {nd }}$ Ed.). New Age International Limited, New Delhi.

Lynch, R. (2009). Strategic Management (5 ${ }^{\text {th }}$ Ed.) India prentice Hall.

Machuki, V. N. (2011). Strategy Implementation: The Influence of Organizational Design .Lambert Academic Publishing.

Magambo, E. (2004). Engines of Rural Development - World Habitat day Award winning Cities UNHabitat

Michael, B. and Russell A. E. S. (2000). Management review, summer 2000.

Mintzberg, H. (1994). Emergent. Strategic Management Journal, 6 (3):257-272.

Muthuiya, F. A, (2004). Strategy Implementation and its Challenges in Non-Profit Organization in Kenya. The case of Africa Medical and Research foundation Kenya (Unpublished MBA project). School of Business, University of Nairobi, Kenya.

Musyoka, M. W. (2000). Challenges Facing Strategy Implementation: A case study of Jomo Kenyatta Foundation (Unpublished MBA research Project). School of Business University of Nairobi, Kenya. 
INTERNATIONAL JOURNAL OF ACADEMIC RESEARCH IN BUSINESS AND SOCIAL SCIENCES

Vol. 9, No. 7, July, 2019, E-ISSN: 2222-6990 ¿C 2019 HRMARS

Noble, C. H. (1996). The Electoral Roots of Strategy Implementation .Research Journal of Business Research, 45:119-134.

Nutt, P. C. (1986) Tactics of Implementation. Academy of Management Journal, 28:230-261.

Okumu, F. (2001). Towards a Strategy Implementation Framework. International Journal of Contemporary Hospital Management, 13:227 - 338.

Pearce, I, J. \& Robison, J. R. (2007). Strategic Management; Formulation Implementation and Control. (6 $6^{\text {th }}$ Ed.). MC Graw Hill. Irin.

Preffer, J. and Sutton, R.I. (1999). The Knowing - Doing Cap. Harvard Business School Press.

Samson, O. O. (2011). The Cooperative Movement in Kenya and its Potential for Enhancement of ICT, Seminar Paper presented to Department of Education Foundation.

Schoap, J. I. (2006). Towards Strategy Implementation an Empirical Study of the Role of Senior. Level Leadership in the Nevada Gaming Industry. UNLV Gaming Research \& Review Journal, 10:1337.

Scholes, K. \& Johnson, G. (1987). Exploring Corporate Strategy. (4 ${ }^{\text {th }}$ Ed). Prentice Hall of India, New Delhi.

Sterling. J. (2003). What Makes a Strategy Work? Strategic Direction, 19 (11): 4-6.

Quinn's, J. (1980). Strategies for Change, Irwin; MC Grawhill.

Yabs, J. (2007). Strategic Management Practice in Kenya, Application and cases. Relax Global Ltd.

Zook, C. and Allen, J. (2001). Profit from the Core. Boston, M. A. Harvard Business School press. 